\title{
Weld speed effects on quality of Ti/Al dissimilar metal joints using laser beam welding
}

\author{
K. Kalaiselvan* \\ Department of Mechanical Engineering, \\ Meenakshi Ramaswamy Engineering College, \\ Ariyalur - Tamil Nadu, 621804, India \\ Email:kalaiesanai@gmail.com \\ *Corresponding author
}
A. Elango
Department of Mechanical Engineering, Alagappa Chettiyar College of Engineering and Technology, Karaikudi - Tamil Nadu, 630004, India Email: elango.arum69@gmail.com

\author{
N.M. Nagarajan \\ Department of Mechanical Engineering, \\ National Institute of Technology, \\ Calicut - Kerala, 673601, India \\ Email: dr.nmnagarajan@gmail.com
}

\begin{abstract}
Laser beam welding produces good quality welds with minimum shrinkage for sheet metal joints. The quality of welded joint depends upon surface morphology, hardness, mixing of liquid phases and metallurgical non-homogeneity induced by gradients of temperatures and cooling rate at the weld interface. In the present investigation, Titanium Grade5 (Ti) and AA2024 (Al) alloy dissimilar sheet metals are joined using Nd:YAG pulsed laser beam and the effect of welding speed on crack tendencies, the strength of weldment based on hardness and composition changes are studied. Test results reveal that higher welding speed eliminates cracks in weldment and improves surface morphology. From hardness test, it is observed that the strength of fusion zone is considerably improved at higher weld speed and the findings are supported by SEM and EDS studies.
\end{abstract}

Keywords: laser beam welding; LBW; morphology; hardness; microstructure; composition.

Reference to this paper should be made as follows: Kalaiselvan, K., Elango, A. and Nagarajan, N.M. (2017) 'Weld speed effects on quality of Ti/Al dissimilar metal joints using laser beam welding', Int. J. Additive and Subtractive Materials Manufacturing, Vol. 1, No. 1, pp.57-66. 
Biographical notes: K. Kalaiselvan is obtained his BE in Mechanical Engineering from Alagappa Chettiyar College of Engineering and Technology, Karaikudi under Madurai Kamaraj University. He did his ME in Manufacturing Engineering from Jayaram College of Engineering under Anna University, Chennai. He teaches subjects like material science, casting and joining processes, manufacturing technology, advanced welding and casting processes, metal forming processes and advanced metrology for both UG and PG students. $\mathrm{He}$ has published ten papers in international journals and four papers in national journals.

A. Elango is a Professor, Head and Vice Principal in A.C. College of Engineering and Technology, Karaikudi. He received his BE in Mechanical Engineering, $\mathrm{ME}$ in Production Engineering and $\mathrm{PhD}$ in Mechanical Engineering from Anna University, Chennai. He has been teaching CAD CAM, robotics and surface engineering for 30 years, in A.C. College of Engineering and Technology, Karaikudi, Tamilnadu, India.

N.M. Nagarajan is a retired Professor from National Institute of Technology, Calicut, Kerala, India. His current research deals with powder metallurgy, metal joining, foundry and control of welding processes. He has authored and co-authored more than 100 technical papers.

\section{Introduction}

Laser beam welding (LBW) opens up many opportunities for designing and economically joining machine parts. Several potential applications of dissimilar Ti and Al weld components are found in aircraft cabin structures (Kocik et al., 2004, 2006), parts of engine cowlings, seat tracks (Kleiner et al., 2009; Möller et al., 2010), components of storage tanks (Leyens and Peters, 2003; Chen et al., 2011a) and elements of the wings (Chen and Nakata, 2009; Katayama, 2009b). These assemblies can be found by adopting welding processes (Katayama, 2009a). The quality of welded dissimilar joints depends upon the cracking tendency, surface morphology, hardness, mixing of liquid phases and metallurgical non-homogeneity induced by gradients of temperature and cooling rate at the weld interface (Squillace et al., 2012; Chen et al., 2011b). Dissimilar welding of Ti and Al using laser beam with extremely high welding speed was tried and the microstructural characteristics of the interface zone in the $\mathrm{Ti}$ and $\mathrm{Al}$ weld were investigated (Lee et al., 2013; Squillace et al., 2012).

The microstructural characteristics in the heat affected zone (HAZ) and fusion zone have been changed after LBW. These are strongly influenced by the welding conditions (Liu et al., 2012). LBW is one of the most efficient joining techniques, due to its flexibility, precision and capability to produce restricted HAZ and deep penetration (Casalino et al., 2014). In particular, pulsed lasers generate a high quality beam, with a low divergence and with a wavelength suitable for the absorption by a wide range of materials (Vänskä and Salminen, 2012; Kraetzsch et al., 2011). LBW processing parameters and physical properties such as laser power, beam diameter, welding speed, focal point position, beam reflectivity, thermal diffusivity, surface tension, edge surface roughness, atmosphere pressure, shielding gas type and shielding gas flow rate (Katayama et al., 2010; Salminen et al., 2010) have a strong effect on the process and weld penetration. 
Better the beam quality, the higher the welding speed. While welding with high power, good beam quality, and wavelength are affected. These are due to high absorption and power density (Zhang et al., 2013). Strength increases with an increase in the welding speed, and therefore extremely high welding speed is good to dissimilar weldability for Ti and Al (Lee et al., 2013). The development of an appropriate system technology and the process development are described, focusing on the main influencing parameters of the process on joint properties (Moller et al., 2011). Temperature, and corresponding heating and cooling rates generate during laser processing of metallic glass. Rapid heating rates during laser processing led to a shift in the onset of crystallisation temperature to a higher level. Faster cooling rates prematurely arrested the crystallite growth yielding much finer crystallite sizes (Joshi et al., 2015).

Considering the above observations the following parameters such as welding speed, heat energy, gas flow rate and focus point position have been selected for this investigation. Experiments with laser welding are carried out to determine the practical operating range by using at various speeds to produce an acceptable quality welding of the dissimilar metals. LBW process has been adopted to produce Ti and aluminium Al alloys thin sheet joints. In the present paper, some aspects of $\mathrm{Ti} / \mathrm{Al}$ dissimilar metal joints such as cracking, surface morphology, hardness, microstructure and composition of fusion zone have been observed and discussed. From this literature survey, it is found that not much work has been reported on dissimilar welding of $\mathrm{Ti} / \mathrm{Al}$ sheet metal. Hence, the present work is under taken to study the welding parameters on quality of weldment.

\section{Experimental details}

The metals used for the investigation are commercially available Titanium Grade5 (Ti) and AA2024 (Al)alloy sheets of $1.0 \mathrm{~mm}$ thickness, $75 \mathrm{~mm}$ width and $150 \mathrm{~mm}$ length. The chemical composition of base metals is listed in Tables 1 and 2 .

Table 1 Chemical composition of Ti (wt. \%)

\begin{tabular}{lccc}
\hline $\mathrm{Al}(\%)$ & $\mathrm{V}(\%)$ & $\mathrm{H}(\%)$ & $\mathrm{Ti}(\%)$ \\
$5.5-6.75$ & $3.5-4.5$ & $0.015(\mathrm{Max})$ & Balance \\
\hline
\end{tabular}

Table 2 Chemical composition of $\mathrm{Al}$ (wt. \%)

\begin{tabular}{lccccccccc}
\hline $\mathrm{Si}(\%)$ & $\mathrm{Cu}(\%)$ & $\begin{array}{c}\mathrm{Zn} \\
(\%)\end{array}$ & $\begin{array}{c}\mathrm{Fe} \\
(\%)\end{array}$ & $\mathrm{Mg}(\%)$ & $\mathrm{Ti}(\%)$ & $\mathrm{V}(\%)$ & $\mathrm{Pb}(\%)$ & $\mathrm{Mn}(\%)$ & $\mathrm{Al}(\%)$ \\
\hline $0.500-1.200$ & $3.800-5.000$ & 0.063 & 0.700 & $0.200-0.800$ & 0.010 & 0.001 & 0.028 & $0.300-1.200$ & Balance \\
\hline
\end{tabular}

For welding, Nd:YAG Pulsed laser welding unit is adopted with repetition pulse range $20 \mathrm{~Hz}$; typical laser power at work piece $500 \mathrm{~W}$; standard beam diameter-600 $\mu \mathrm{m}$; pulse width ranges $8.5 \mathrm{~ms}$; focusing length $200 \mathrm{~mm}$ and gas flow rate $10 \mathrm{lit} / \mathrm{min}$. Dissimilar metal is welded by varying welding speed namely 180, 190, 200, 210, 220, 230 and $240 \mathrm{~mm} / \mathrm{min}$. Argon shielding gas is used to prevent oxidation of molten surface during welding. Laser offset distance is kept at $0.3 \mathrm{~mm}$ focusing from the Al side and weld joint gap is maintained with $0.1 \mathrm{~mm}$. A butt joint is made using two jig plates. No special heat treatment and edge preparation are carried out before laser welding. In particular, the 
Ti-Al dissimilar joints are positioned and the laser beam is projected from the Al side, forming the weld between the two alloys.

Figure 1 shows the welding jig installed for dissimilar welding of Ti and Al alloy thin sheets. After welding, the macrostructure of weldment is examined using Tool Makers Microscope (Model: CM0646). Test specimens from the weldment are cut to the required dimensions and then polished using different grades of emery papers and are subjected to metallographic examinations using scanning electron microscope (SEM-Hitachi SU6600) and energy dispersive spectroscope (EDS), which is used to reveal various features of the joint including percentage composition. Hardness distribution on weldment is carried out using Rockwell Hardness Tester (LS 1586-1968).

Figure 1 Welding jig (see online version for colours)

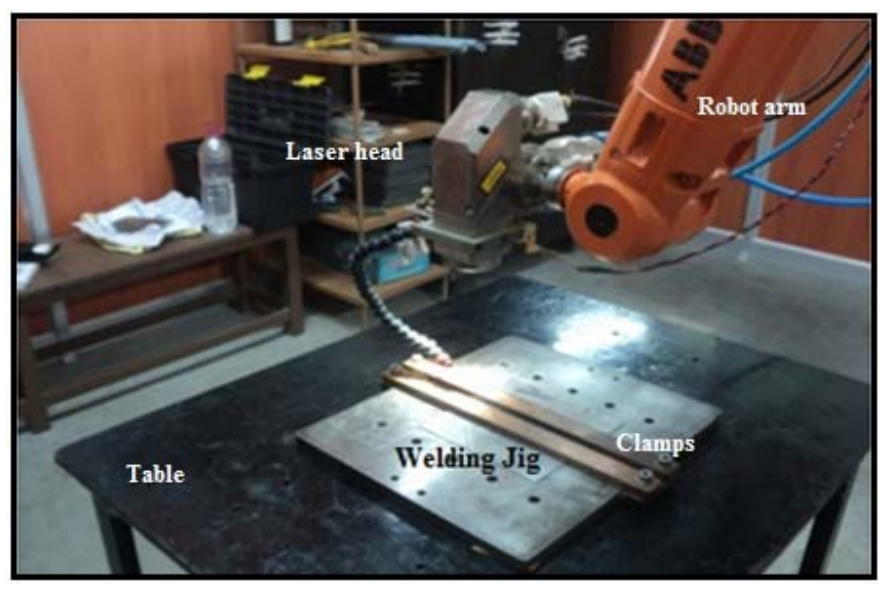

\section{Results and discussions}

The effect of weld speed on variables such as crack tendency and surface morphology, hardness, microstructure and composition changes are found and discussed below.

\subsection{Crack and surface morphology}

Figure 2 shows the appearances of weld beads of $\mathrm{Ti}$ and $\mathrm{Al}$ dissimilar welding at $180 \mathrm{~mm} / \mathrm{min}$ under focal conditions. Full penetration weld is obtained and longitudinal crack has been seen on the weld bead surface. These weld cracks and surface morphology are viewed using Tool Makers Microscope with magnification X10.

These cracks are formed due to uneven heat flow between $\mathrm{Ti}$ and $\mathrm{Al}$ sides results the formation of the intermetallic compound (Chen et al., 201). Relatively good welds and surface morphology are observed in all the weld beads at higher weld speeds except crack formation at lower speeds observed namely $190 \mathrm{~mm} / \mathrm{min}$ and a180 $\mathrm{mm} / \mathrm{min}$. The weld bead width is getting narrower with an increase in weld speed from $200 \mathrm{~mm} / \mathrm{min}$ to $240 \mathrm{~mm} / \mathrm{min}$. Figure 3 shows surface morphology of weld bead at $240 \mathrm{~mm} / \mathrm{min}$. 
Figure 2 Crack at speed $180 \mathrm{~mm} / \mathrm{min}$ (see online version for colours)

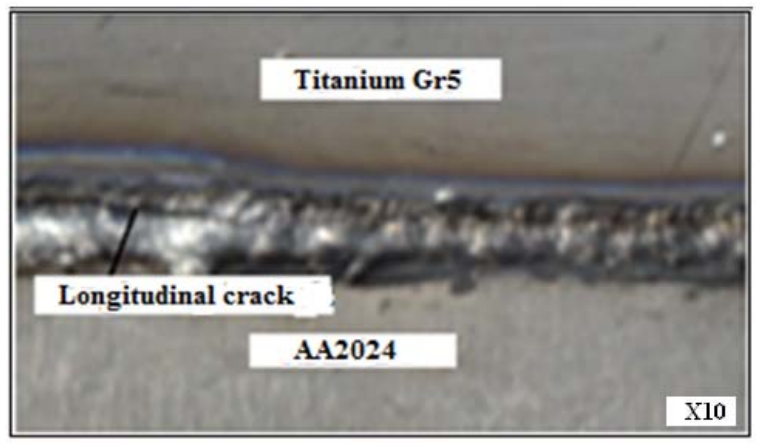

Figure 3 Surface morphology at speed $240 \mathrm{~mm} / \mathrm{min}$ (see online version for colours)

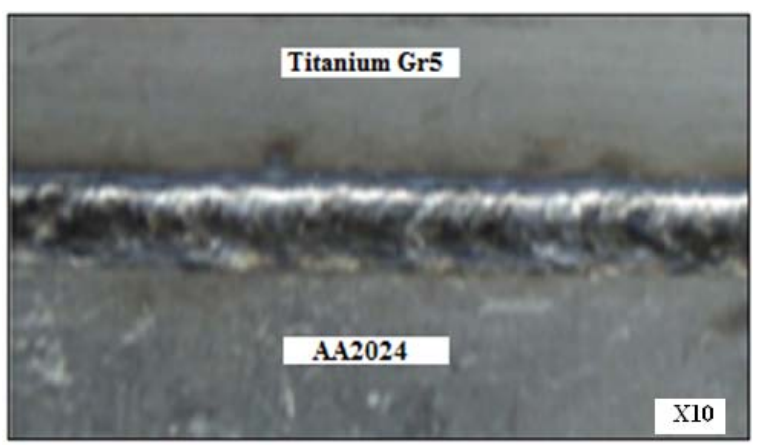

As the welding speed increases, crack formation tendency gets eliminated in Ti/Al joints. Also, clean surface morphology is noted at higher welding speeds.

\subsection{Hardness}

The strength of the weldment is estimated based on hardness values. Heat energy is focused from the Al side with an offset distance of $0.3 \mathrm{~mm}$ and the sheets are welded using a laser beam. After welding, the hardness values are measured using Rockwell Hardness (HRC) scale (https://en.wikipedia.org/wiki/Rockwell_scale). As per American Society for Testing and Materials (ASTM-E18: Standard methods for Rockwell hardness) direction, diamond indentor is used for $\mathrm{C}$ scale readings. Accordingly in the present investigation, only HRC scale is used for uniformity to find hardness of Ti and Al alloy dissimilar weld. Hardness tests are performed to evaluate the hardness distribution across the weld line, namely the base metals and HAZ on both sides of the weld region left and right. Hardness measurements are taken on the test piece with $1 \mathrm{~mm}$ gap as per the locations shown in Figure 4 and the laser beam is focused from the Al side for welding. 
Figure 4 Hardness measurements locations

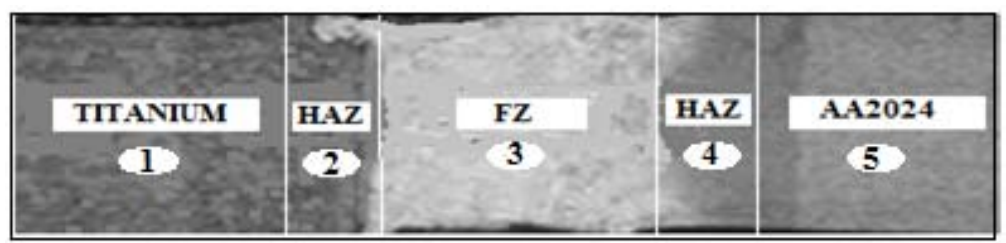

Hardness distribution across the weld region is given in Figure 5. Test results reveal that the hardness of the fusion zone is slightly lower than that of HAZ and base metal as seen from titanium side. However, from Al side, the hardness at the fusion zone is higher. This may be due to the difference in melting temperature of dissimilar metals $\left(\mathrm{Al}-660^{\circ} \mathrm{C}\right.$, $\mathrm{Ti}-1660^{\circ} \mathrm{C}$ ). This is similar that of High Speed tool Steel where 18 percentage Tungsten addition in steel results increase in hot hardness value. However, proper mixing of these two metals is observed in the weld zone as the hardness value of fusion zone is found higher than HAZ and base metal zone, viewed from Al side.

Figure 5 Hardness distributions across the weld region

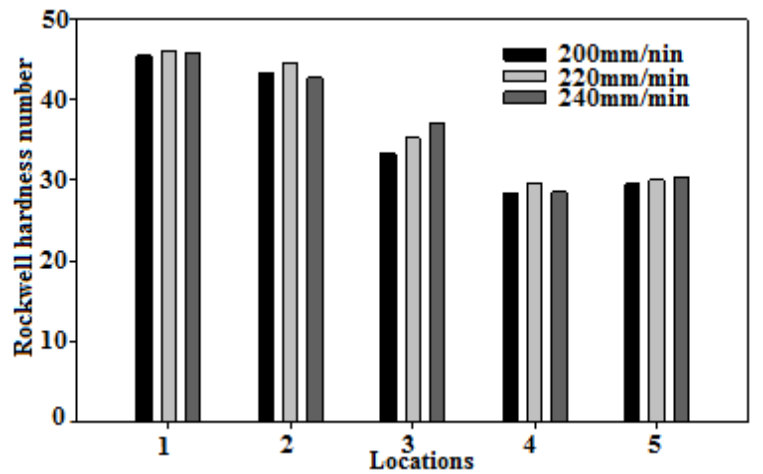

Higher heat input associated with weld speed leads to increase in hardness at HAZ. However as the laser beam heat affects the Al side, Al gets softened due to its low melting point and hardness is considerably reduced even at the base metal zone.

\subsection{Microstructure}

In welding, the grain boundaries in the HAZ can be linked with the fusion zone. During solidification, elements can diffuse into the HAZ from the fusion zone along the grain boundaries. The dissolved elements and impurities diffuse more rapidly along the grain boundaries resulting in a local reduction of melting temperature. The microstructures in the fusion zone are a result of solidification behaviour and subsequent solid-phase transformation, which are controlled by composition and weld cooling rates. Fusion zone of a dissimilar metal joint depends on the melting ratio of the two metals to be joined and related to welding parameters. The grain structure with a magnification of X5000 at the position of HAZ and FZ for speed at $200 \mathrm{~mm} / \mathrm{min}$ is shown in Figure 6(a), Figure 6(b) and Figure 6(c). It is observed that higher heat input associated with lower welding speed results fine grains in titanium HAZ (a) and coarse grains in aluminium HAZ (c). All 
samples are viewed through SEM after surface preparation explained under experimental details.

Figure 6 Microstructure at $200 \mathrm{~mm} / \mathrm{min}$, (a) Ti-HAZ (b) fusion zone (c) Al-HAZ

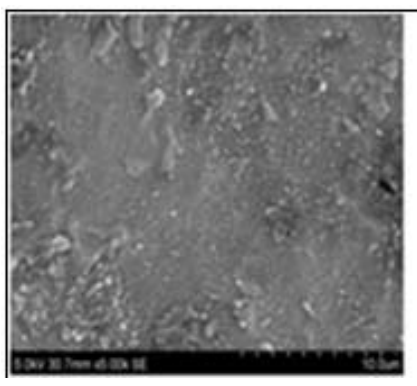

(a)

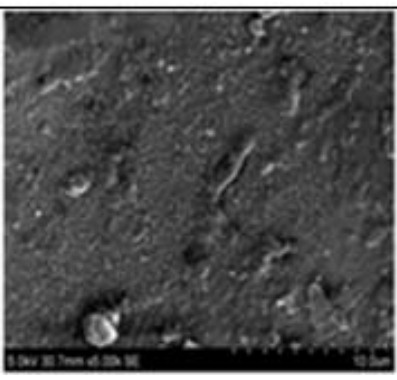

(b)

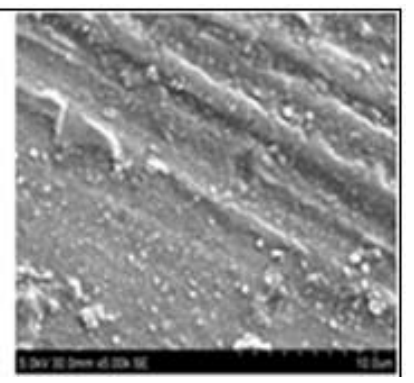

(c)

Figure 7(a), Figure 7(b) and Figure 7(c) show fine grain structures at the speed of $240 \mathrm{~mm} / \mathrm{min}$. it is noted that grain size decreases with increase in speed. Comparing with weld speed $200 \mathrm{~mm} / \mathrm{min}$, at $240 \mathrm{~mm} / \mathrm{min}$ grain structures are uniformly distributed and are smooth in texture. Thus, higher welding lead to grain refinement both in fusion and HAZs.

Figure 7 Microstructure at $240 \mathrm{~mm} / \mathrm{min}$, (a) Ti-HAZ (b) fusion zone (c) Al-HAZ

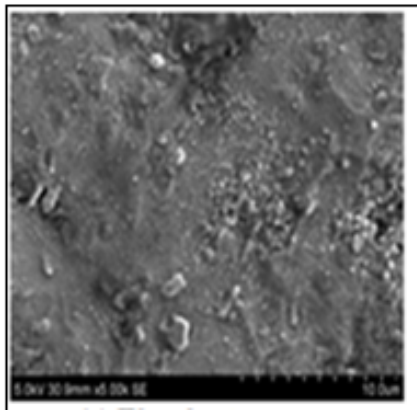

(a)

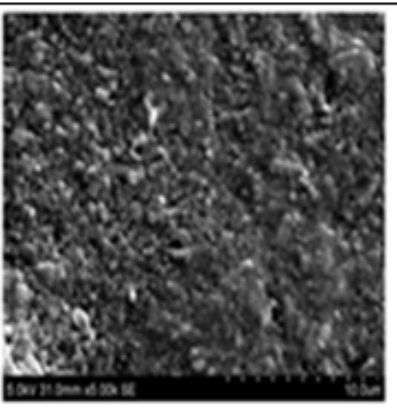

(b)

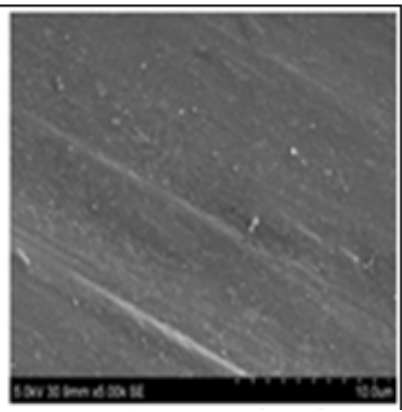

(c)

\subsection{Chemical composition of the weld region analysis}

Energy dispersive X-ray spectroscopy (EDS) spectrum and chemical composition analysis are carried out on weld seam region at speed $200 \mathrm{~mm} / \mathrm{min}$ and is shown in Figure 8 . Spectrum processing indicates that Al with original composition $92 \%$ in parent metal is reduced to $76.33 \%$ of weight in fusion zone, whereas Ti content is increased to $11.04 \%$ from $0.01 \%$ (Table 2). Thus, the strength of weld joined is improved due to increased mixing of Ti content. 
Figure 8 EDS fusion zone analysis at $200 \mathrm{~mm} / \mathrm{min}$ (see online version for colours)

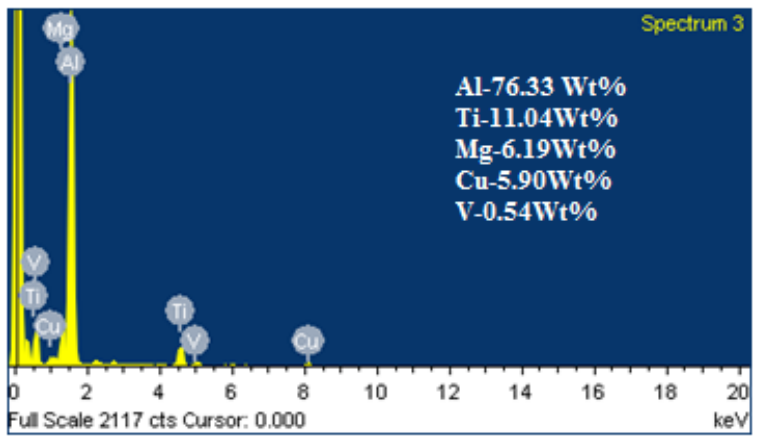

It is seen that welding speed is an important factor on heat flow in welding. These, in turn, affect the metal penetration depth, shape and final solidification structure of the fusion zone. Both shape and microstructure of the fusion zone are influencing considerably the properties at the weldment. The sample at the speed of $240 \mathrm{~mm} / \mathrm{min}$ formed at the fusion zone is observed by EDS and is shown in Figure 9.

Figure 9 EDS fusion zone analysis at $240 \mathrm{~mm} / \mathrm{min}$ (see online version for colours)

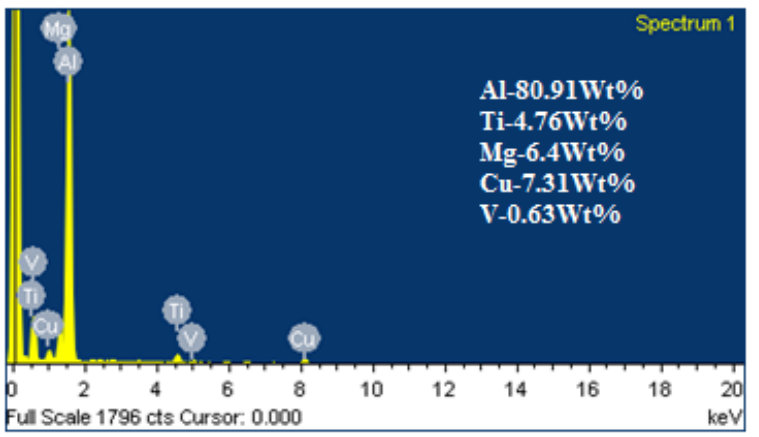

Spectrum analysis indicates that $\mathrm{Al}$ content is enhanced to $80.91 \%$ whereas Ti content is reduced to $4.76 \%$ and results further increase in hardness at $240 \mathrm{~mm} / \mathrm{min}$. It is observed that reduction in $\mathrm{Ti}$ is not affecting the increasing trend of hardness, as $0.01 \% \mathrm{Ti}$ is enhanced to $4.76 \%$ in $\mathrm{Al}$ alloy. This finding is also supported by the higher hardness distribution at fusion zone viewed from the Al side as per Figure 5. Hence, higher welding speed improves the strength of dissimilar weld joints.

\section{Conclusions}

From the experimental investigations, the following are the conclusions.

1 As the welding speed increases interface cracking tendency in Ti/Al alloy weldment gets reduced and eliminated. Also, clean surface morphology is obtained.

2 At high speeds, the hardness on fusion zone is improved compared with base metal, viewed from the Al side. 
3 SEM studies reveal that increase in weld speed improves grain refinements resulting strong weldment.

4 Spectrum analysis indicates that increase in weld speed increases Al content and Ti content in the weldment and improves the strength of dissimilar sheet metal joints.

\section{Acknowledgements}

The authors are grateful to the Centre for Materials Joining and Research (CEMAJOR), Department of Manufacturing Engineering, Annamalai University, Annamalainagar, Tamil Nadu, India for extending the facilities of Materials Testing Laboratory to carry out this investigation.

\section{References}

Casalino, G., Mortello, M.A., Leo, P., Benyounis, K.Y. and Olabi, A.G. (2014) 'Study on arc and laser powers in the hybrid welding of AA5754 Al-alloy', Materials and Design, September 2014, Vol. 61, pp.191-198.

Chen, S., Li, L., Chen, Y. and Huang, J. (2011a) 'Joining mechanism of Ti/Al dissimilar alloys during laser welding-brazing process', Journal of Alloys and Compounds, Vol. 509, No. 3, pp.891-898.

Chen, S., Li, L., Chen, Y., Dai, J. and Huang, J. (2011b) 'Improving interfacial reaction nonhomogeneity during laser welding-brazing $\mathrm{Al}$ to Ti', Mat. and Des., Vol. 32, No. 8, pp.4408-4416.

Chen, Y., Chen, S. and Li, L. (2010) 'Influence of interfacial reaction layer morphologies on crack initiation and propagation in Ti/Al joint by laser welding-brazing', Materials and Design, January, Vol. 31, No. 1, pp.227-233.

Chen, Y.C. and Nakata, K. (2009) 'Microstructural characterization and mechanical properties in friction stir welding of aluminum and titanium dissimilar alloys', Materials and Design, Vol. 30, No. 3, pp.469-474.

Joshi, S.S., Gkriniari, A.V., Katakam, S. and Dahotre, N.B. (2015) 'Dynamic crystallization during non-isothermal laser treatment of Fe-Si-B metallic glass', Journal of Physics D: Applied Physics, Vol. 48, No. 49, p.495501.

Katayama, S. (2009a) 'Laser welding for manufacturing innovation', Journal of the Japan Welding Society, Vol. 78, No. 8, pp.682-692.

Katayama, S. (2009b) 'Laser welding', Journal of the Japan Welding Society, Vol. 78, No. 2, pp.124-138.

Katayama, S., Kawahito, Y. and Mizutani, M. (2010) 'Elucidation of laser welding phenomena and factors affecting weld penetration and welding defects', Physics Procedia, Vol. 5, Part B, pp.9-17.

Kleiner, M., Tekkaya, A.E., Becker, D., Pietzka, D. and Schikorra, M. (2009) 'Combination of curved profile extrusion and composite extrusion for increased lightweight properties', Prod. Eng. Res. Devel., p.3.

Kocik, R., Kaschel, S., Kreimeyer, M., Schumacher, J. and Vollertsen, F. (2004) 'Development of a new joining technology for hybrid metal aircraft structures', The 23rd International Congress on Application of Lasers and Electro-Optics, pp.707-716.

Kocik, R., Vugrin, T. and Seefeld, T. (2006) 'Laserstrahischweibenimflugzeugbau: stand und kunftigueanwendungen', Proceedings 5, Laser-anwenderforum, pp.15-26, Bremen. 
Kraetzsch, M., Standfuss, J., Klotzbach, A., Kaspar, J., Brenner, B. and Beyer, E. (2011) 'Laser beam welding with high-frequency beam oscillation': welding of dissimilar materials with brilliant fiber lasers', Physics Procedia, Vol. 12, Part A, pp.142-149.

Lee, J-J., Nakamura, H., Kawahito, Y. and Katayama, S. (2013a) 'Microstructural characteristics and mechanical properties of single mode fiber laser lap welded joint in $\mathrm{Ti}$ and $\mathrm{Al}$ dissimilar metal', Transactions of JWRI, Vol. 42, No. 1, pp.17-21.

Lee, S.J., Nakamura, H., Kawahito, Y. and Katayama, S. (2013b) 'Weldability of Ti and Al dissimilar metals using single-mode fiber laser', Journal of Laser Micro/Nano Engineering, Vol. 8, No. 2, pp.149-154.

Leyens, C. and Peters, M. (2003) Titanium and Titanium Alloys; Fundamentals and Applications, WILEY-VCH GmbH \& Co. KGaA, Weinheim.

Liu, H., Nakata, K., Yamamoto, N. and Liao, J. (2012) 'Microstructural characteristics and mechanical properties in laser beam welds of Ti6Al4V alloy', Journal of Materials Science, Vol. 47, No. 3, pp.1460-1470.

Moller, F., Grden, M., Thomy, C. and Vollertsen, F. (2011) 'Combined laser beam welding and brazing process for aluminium titanium hybrid structures', Physics Procedia, Vol. 12, Part A, pp.215-223.

Möller, F., Thomy, C. and Vollertsen, F. (2010) Joining of Titanium-Aluminium Seat Tracks for Aircraft Applications - System Technology and Joint Properties, IIW Assembly 2010 Com, XVII Istanbul, Turkey IIW-Doc. XVII-0005-2010, CD-Rom.

Salminen, A., Piili, H. and Purtonen, T. (2010) 'The characteristics of high power fibre laser welding', Proceeding of the Institution of Mechanical Engineers Part C: Journal of Mechanical Engineering Science, Vol. 224, pp.1019-1029.

Squillace, A., Prisco, U., Ciliberto, S. and Astarita, A. (2012) 'Effect of welding parameters on morphology and mechanical properties of Ti-6Al-4V laser beam welded butt joints', Journal of Materials Processing Technology, Vol. 212, No. 2, pp.427-436.

Vänskä, M. and Salminen, A. (2012) 'Laser welding of stainless steel self-steering tube-to-tube joints with oscillating mirror', Proceedings of the Institute of Mechanical Engineering, Part B: Journal of Engineering Manufacture, Vol. 226, No. 4, pp.632-640.

Zhang, M., Chen, G., Zhou, Y. and Liao, S. (2013) 'Optimization of deep penetration laser welding of thick stainless steel with a $10 \mathrm{~kW}$ fiber laser', Materials and Design, September 2014, Vol. 53, pp.568-576.

\section{Websites}

https://en.wikipedia.org/wiki/Rockwell_scale. 